\title{
New classes of polynomial maps satisfying the real Jacobian conjecture in $\mathbb{R}^{2}$
}

\author{
JACKSON ITIKAWA ${ }^{1}$ and JAUME LLIBRE ${ }^{2}$ \\ ${ }^{1}$ Departamento de Matemática, Universidade Federal de Rondônia, Campus - BR 364, Km 9.5, 76801-059 \\ Porto Velho, RO, Brazil \\ ${ }^{2}$ Department de Matemàtiques, Universitat Autònoma de Barcelona, 08193 Bellaterra, \\ Barcelona, Catalonia, Spain
}

Manuscript received on September 14, 2017; accepted for publication on August 23, 2018

\begin{abstract}
How to cite: ITIKAWA J AND LLIBRE J. 2019. New classes of polynomial maps satisfying the real Jacobian conjecture in $\mathbb{R}^{2}$. An Acad Bras Cienc 91: e20170627. DOI 10.1590/10.1590/0001-3765201920170627.

Abstract: We present two new classes of polynomial maps satisfying the real Jacobian conjecture in $\mathbb{R}^{2}$. The first class is formed by the polynomials maps of the form $(q(x)-p(y), q(y)+p(x)): \mathbb{R}^{2} \rightarrow \mathbb{R}^{2}$ such that $\mathrm{p}$ and $\mathrm{q}$ are real polynomials satisfying $\mathrm{p}^{\prime}(\mathrm{x}) \mathrm{q}^{\prime}(\mathrm{x}) \neq 0$. The second class is formed by polynomials maps $(\mathrm{f}, \mathrm{g}): \mathbb{R}^{2} \rightarrow \mathbb{R}^{2}$ where $\mathrm{f}$ and $\mathrm{g}$ are real homogeneous polynomials of the same arbitrary degree satisfying some conditions.
\end{abstract}

Key words: injective polynomial maps, global center, real Jacobian conjecture, planar Hamiltonian systems

\section{INTRODUCTION}

Let $\mathrm{F}=(\mathrm{f}, \mathrm{g}): \mathbb{R}^{2} \rightarrow \mathbb{R}^{2}$ be a polynomial map such that its Jacobian never vanishes. The celebrated real Jacobian conjecture states that under these conditions F is injective. This conjecture goes back to 1939, see Keller (1939).

In 1994 Pinchuk (1994) found a map F = (f, g) with $\mathrm{f}$ and $\mathrm{g}$ polynomials of degree 10 and 25 respectively, and with Jacobian strictly positive, such that $\mathrm{F}$ is not injective.

Although the real Jacobian conjecture has been proved false by Pinchuk, a considerable number of papers has been devoted to this subject, mainly searching for additional conditions such that the conjecture might hold. The problem of determining if $\mathrm{F}$ is injective in the case of its Jacobian to be a non-zero constant, known as the Jacobian conjecture, is still open, see Essen (2000) and the references therein for more information.

Correspondence to: Jackson Itikawa

E-mail: itikawa@unir.br

ORCid: https://orcid.org/0000-0002-8268-0016

2010 Mathematics Subject Classification.

Primary 14R15, 34C25, 37C05, 37C10, 37J45. 


\section{MAIN RESULTS}

In this note we present two new classes of polynomial maps that satisfies the real Jacobian conjecture. In what follows we present our main results.

Theorem 1. Let $\mathrm{p}$ and $\mathrm{q}$ be real polynomials of one variable and consider the polynomial map $\mathrm{F}=(\mathrm{f}, \mathrm{g})$ : $\mathbb{R}^{2} \rightarrow \mathbb{R}^{2}$ with $\mathrm{f}=\mathrm{f}(\mathrm{x}, \mathrm{y})=\mathrm{q}(\mathrm{x})-\mathrm{p}(\mathrm{y}), \mathrm{g}=\mathrm{g}(\mathrm{x}, \mathrm{y})=\mathrm{q}(\mathrm{y})+\mathrm{p}(\mathrm{x})$ and $\mathrm{p}^{\prime}(\mathrm{x}) \mathrm{q}^{\prime}(\mathrm{x}) \neq 0$. Then the Jacobian of polynomial map $\mathrm{F}$ never vanish and $\mathrm{F}$ is injective.

Theorem 1 is proved in the section Proofs of the Theorems.

As usual here $p^{\prime}(x)$ denotes the derivative of $p$ with respect to the variable $x$, and if $f=f(x, y)$ we denote by $f_{x}$ the partial derivative of $f$ with respect to the variable $x$. Similarly is defined $f_{y}$.

Theorem 2. Let $\mathrm{f}$ and $\mathrm{g}$ be real homogeneous polynomials of the same degree in the variables $\mathrm{x}$ and $\mathrm{y}$ such that

(i) the Jacobian of the polynomial map $\mathrm{F}=(\mathrm{f}, \mathrm{g}): \mathbb{R}^{2} \rightarrow \mathbb{R}^{2}$ never vanish,

(ii) $\mathrm{f}$ and $\mathrm{g}$ have no real linear factors in common,

(iii) the polynomials $\mathrm{P}=-\mathrm{ff}_{\mathrm{y}}-\mathrm{gg}_{\mathrm{y}}$ and $\mathrm{Q}=\mathrm{ff}_{\mathrm{x}}+\mathrm{gg}_{\mathrm{x}}$ have no real common factors, and

(iv) $\int_{-\infty}^{+\infty} \frac{\mathrm{P}(1, \mathrm{y})}{\mathrm{Q}(1, \mathrm{y})-\mathrm{yP}(1, \mathrm{y})} \mathrm{dy}=0$.

Then the polynomial map $\mathrm{F}$ is injective.

Theorem 2 is also proved in the section Proofs of the Theorems.

Other classes of polynomial maps satisfying the real Jacobian conjecture were given in Braun and Llibre (2015) and Braun et al. (2016).

\section{PRELIMINARY RESULTS}

Let $\mathrm{P}$ and $\mathrm{Q}$ be polynomials in the variables $\mathrm{x}$ and $\mathrm{y}$. Consider the polynomial differential system

$$
\dot{\mathrm{x}}=\mathrm{P}(\mathrm{x}, \mathrm{y}), \quad \dot{\mathrm{y}}=\mathrm{Q}(\mathrm{x}, \mathrm{y}) .
$$

We say that an isolated singularity $\mathrm{p}$ of system (1) is a center when there is a neighborhood $\mathrm{V}_{\mathrm{p}} \subset \mathrm{U}$ of $\mathrm{p}$ such that every solution in $\mathrm{V}_{\mathrm{p}} \backslash\{\mathrm{p}\}$ is periodic. The biggest open connected set containing $\mathrm{p}$, denoted by $\mathrm{W}_{\mathrm{p}} \subset \mathrm{U}$, such that $\mathrm{W}_{\mathrm{p}} \backslash\{\mathrm{p}\}$ is filled with periodic orbits is called the period annulus of the center. If $\mathrm{W}_{\mathrm{p}}=\mathbb{R}^{2}$ then $\mathrm{p}$ is a global center of system (1).

Let $q$ be an isolated singularity of system (1). If $X=(P, Q)$ then $D X(q)$ is the Jacobian matrix of system (1) at $\mathrm{q}$. If $\operatorname{det}(\mathrm{DX}(\mathrm{q})) \neq 0$ then we say that $\mathrm{q}$ is a non-degenerate singular point. Under these assumptions a necessary condition in order that $q$ be a center is that the eigenvalues of DX(q) are purely imaginary. Such a center is a non-degenerate center.

The polynomial differential system (1) is a Hamiltonian system if there is a polynomial $\mathrm{H}$ such that $\mathrm{P}(\mathrm{x}, \mathrm{y})=-\mathrm{H}_{\mathrm{y}}(\mathrm{x}, \mathrm{y})$ and $\mathrm{Q}(\mathrm{x}, \mathrm{y})=\mathrm{H}_{\mathrm{x}}(\mathrm{x}, \mathrm{y})$. Then the polynomial $\mathrm{H}$ is called the Hamiltonian of the Hamiltonian system (1). 
The following result is due to Sabatini, see Theorem 2.3 of Sabatini (1998). This result provides a relation between the real Jacobian conjecture and the global centers of some polynomial Hamiltonian systems.

Theorem 3. Let $\mathrm{F}=(\mathrm{f}, \mathrm{g}): \mathbb{R}^{2} \rightarrow \mathbb{R}^{2}$ be a polynomial map such that its Jacobian never vanishes and $\mathrm{F}(0,0)=$ $(0,0)$. Then the following statements are equivalent.

(a) The polynomial Hamiltonian system with Hamiltonian $\mathrm{H}=\left(\mathrm{f}(\mathrm{x}, \mathrm{y})^{2}+\mathrm{g}(\mathrm{x}, \mathrm{y})^{2}\right) / 2$ has a global center at the origin of coordinates.

(b) The map $\mathrm{F}$ is a global diffeomorphism of $\mathbb{R}^{2}$ onto itself.

In addition we present the following result due to Braun and Llibre, see Lemma 1 of Braun and Llibre (2017).

Lemma 4. Let $\mathrm{F}=(\mathrm{f}, \mathrm{g}): \mathrm{U} \rightarrow \mathbb{R}^{2}$ be a $\mathscr{C}^{2}$ function defined in an open connected set $\mathrm{U} \subset \mathbb{R}^{2}$ and $\left(\mathrm{x}_{0}, \mathrm{y}_{0}\right) \in \mathrm{U}$ such that the Jacobian of $\mathrm{F}$ in $\left(\mathrm{x}_{0}, \mathrm{y}_{0}\right)$ does not vanish. Moreover consider the Hamiltonian $\mathrm{H}=\left(\mathrm{f}(\mathrm{x}, \mathrm{y})^{2}+\mathrm{g}(\mathrm{x}, \mathrm{y})^{2}\right) / 2$. Then $\left(\mathrm{x}_{0}, \mathrm{y}_{0}\right)$ is a singular point of the polynomial Hamiltonian system $\dot{\mathrm{x}}=-\mathrm{H}_{\mathrm{y}}$, $\dot{\mathrm{y}}=\mathrm{H}_{\mathrm{x}}$ if and only if $\mathrm{F}\left(\mathrm{x}_{0}, \mathrm{y}_{0}\right)=(0,0)$. Under these conditions $\left(\mathrm{x}_{0}, \mathrm{y}_{0}\right)$ is a non-degenerate center and also an isolated global minimum of $\mathrm{H}$. In particular if the Jacobian of $\mathrm{F}$ never vanishes in $\mathrm{U}$ all the singular points of the Hamiltonian system $\dot{\mathrm{x}}=-\mathrm{H}_{\mathrm{y}}, \dot{\mathrm{y}}=\mathrm{H}_{\mathrm{x}}$ in $\mathrm{U}$ are non-degenerate centers and are the zeros of the $\operatorname{map} \mathrm{F}$.

\section{THE POINCARÉ COMPACTIFICATION}

The set $\mathbb{S}^{2}=\left\{\mathrm{y}=\left(\mathrm{y}_{1}, \mathrm{y}_{2}, \mathrm{y}_{3}\right) \in \mathbb{R}^{3}: \mathrm{y}_{1}^{2}+\mathrm{y}_{2}^{2}+\mathrm{y}_{3}^{2}=1\right\}$ is called the Poincaré sphere. Consider $\mathrm{T}_{\mathrm{y}} \mathbb{S}^{2}$ the tangent space to the Poincaré sphere at the point y and the central projection $\mathrm{f}: \mathrm{T}_{(0,0,1)} \mathbb{S}^{2} \rightarrow \mathbb{S}^{2}$.

Let $\mathrm{X}$ be a polynomial vector field of degree $\mathrm{n}$ in the plane $\mathrm{T}_{(0,0,1)} \mathbb{S}^{2}$. The map f defines 2 copies of $\mathrm{X}$ in $\mathbb{S}^{2}$, one in the northern hemisphere and the other in the southern hemisphere. Let $\mathrm{X}^{\prime}$ be the vector field Df $\circ X$ defined on the Poincaré sphere except on its equator $\mathbb{S}^{1}=\left\{y \in \mathbb{S}^{2}: y_{3}=0\right\}$. We remark that $\mathrm{X}^{\prime}$ is everywhere tangent to $\mathbb{S}^{2}$ and $\mathbb{S}^{1}$ is identified to the infinity of $\mathbb{R}^{2}$. We define $\mathrm{p}(\mathrm{X})$, the Poincaré compactified vector field associated to $\mathrm{X}$ as the analytic extension of $\mathrm{y}_{3}^{\mathrm{n}-1} \mathrm{X}^{\prime}$ to $\mathbb{S}^{2}$. Note that studying the behavior of $\mathrm{p}(\mathrm{X})$ around $\mathbb{S}^{1}$, we obtain the behavior of $\mathrm{X}$ at infinity. Also, $\mathbb{S}^{1}$ is invariant under the flow of $\mathrm{p}(\mathrm{X})$.

The Poincaré disc is the projection of the closed northern hemisphere of $\mathbb{S}^{2}$ on $\mathrm{y}_{3}=0$ under $\left(\mathrm{y}_{1}, \mathrm{y}_{2}, \mathrm{y}_{3}\right) \longmapsto\left(\mathrm{y}_{1}, \mathrm{y}_{2}\right)$.

The singular points of $\mathrm{p}(\mathrm{X})$ in the interior of the Poincaré disc, or equivalently in open northern hemisphere $\left\{\left(\mathrm{y}_{1}, \mathrm{y}_{2}, \mathrm{y}_{3}\right) \in \mathbb{S}^{2}: \mathrm{y}_{3}>0\right\}$, are called the finite singular points of $\mathrm{X}$. While the singular points of $\mathrm{p}(\mathrm{X})$ contained in $\mathbb{S}^{1}$ are called the infinite singular points of $\mathrm{X}$.

For more details on the Poincaré compactification, see chapter 5 of Dumortier et al. (2006).

The following result is the Poincaré-Hopf Theorem for the Poincaré compactification of a polynomial vector field. For a proof see for instance Theorem 6.30 of Dumortier et al. (2006).

Theorem 5. Let $\mathrm{X}$ be a polynomial vector field. If $\mathrm{p}(\mathrm{X})$ defined on the Poincaré sphere $\mathbb{S}^{2}$ has finitely many singular points, then the sum of their topological indices is two. 


\section{PROOFS OF THE THEOREMS}

Proof of Theorem 1. We claim that the Jacobian of $\mathrm{F}$ is $\mathrm{q}^{\prime}(\mathrm{x}) \mathrm{q}^{\prime}(\mathrm{y})+\mathrm{p}^{\prime}(\mathrm{x}) \mathrm{p}^{\prime}(\mathrm{y})>0$. Indeed, since $\mathrm{p}^{\prime}(\mathrm{x}) \mathrm{q}^{\prime}(\mathrm{y}) \neq$ 0 each one of the one-variable polynomials $\mathrm{p}^{\prime}(\mathrm{x}), \mathrm{q}^{\prime}(\mathrm{y})$ is either strictly positive or strictly negative. Consider the case $\mathrm{p}^{\prime}(\mathrm{x})>0$ and $\mathrm{q}^{\prime}(\mathrm{y})<0$, the other cases can be done similarly. Then $\mathrm{p}^{\prime}(\mathrm{x}) \mathrm{q}^{\prime}(\mathrm{y})<0$. But whatever the signals of each of these polynomials are, we have that $\mathrm{p}^{\prime}(\mathrm{x}) \mathrm{p}^{\prime}(\mathrm{y})>0$ and $\mathrm{q}^{\prime}(\mathrm{x}) \mathrm{q}^{\prime}(\mathrm{y})>0$, consequently $\mathrm{q}^{\prime}(\mathrm{x}) \mathrm{q}^{\prime}(\mathrm{y})+\mathrm{p}^{\prime}(\mathrm{x}) \mathrm{p}^{\prime}(\mathrm{y})>0$, and the claim is proved.

From the claim we have that the polynomial map $F=(f, g)$ with $f=q(x)-p(y), g=q(y)+p(x)$ satisfies the assumptions of Lemma 4 with $U=\mathbb{R}^{2}$. Hence all the singular points of the polynomial Hamiltonian system with Hamiltonian $\mathrm{H}=\left(\mathrm{f}(\mathrm{x}, \mathrm{y})^{2}+\mathrm{g}(\mathrm{x}, \mathrm{y})^{2}\right) / 2$ are non-degenerated centers.

We study the infinite singular points of the system

$$
\dot{\mathrm{x}}=\mathrm{P}=-\mathrm{H}_{\mathrm{y}}=-\mathrm{ff}_{\mathrm{y}}-\mathrm{gg}_{\mathrm{y}}, \quad \dot{\mathrm{y}}=\mathrm{Q}=\mathrm{H}_{\mathrm{x}}=\mathrm{ff}_{\mathrm{x}}+\mathrm{gg}_{\mathrm{x}},
$$

where $\mathrm{f}=\mathrm{q}(\mathrm{x})-\mathrm{p}(\mathrm{y}), \mathrm{g}=\mathrm{q}(\mathrm{y})+\mathrm{p}(\mathrm{x})$ with $\mathrm{p}(\mathrm{x})=\mathrm{ax} \mathrm{x}^{\mathrm{n}}+$ l.o.t., $\mathrm{q}(\mathrm{x})=\mathrm{bx} \mathrm{m}^{\mathrm{m}}+$ l.o.t., $\mathrm{n}$ and $\mathrm{m}$ positive integers, $\mathrm{ab} \neq 0$, and l.o.t. means lower order terms of the polynomial.

First we assume that $\mathrm{n}=\mathrm{m}$. For studying the infinite equilibria consider the homogeneous polynomial $\mathrm{yP}_{2 \mathrm{n}-1}(\mathrm{x}, \mathrm{y})-\mathrm{xQ}_{2 \mathrm{n}-1}(\mathrm{x}, \mathrm{y})$ of degree $2 \mathrm{n}$, where $\mathrm{P}_{2 \mathrm{n}-1}$ and $\mathrm{Q}_{2 \mathrm{n}-1}$ are the homogeneous parts of degree $2 \mathrm{n}-1$ of the polynomials $\mathrm{P}$ and $\mathrm{Q}$ respectively.

Since $\mathrm{yP}_{2 \mathrm{n}-1}(\mathrm{x}, \mathrm{y})-\mathrm{xQ}_{2 \mathrm{n}-1}(\mathrm{x}, \mathrm{y})=-\mathrm{n}\left(\mathrm{a}^{2}+\mathrm{b}^{2}\right)\left(\mathrm{x}^{2 \mathrm{n}}+\mathrm{y}^{2 \mathrm{n}}\right) \neq 0$ for $(\mathrm{x}, \mathrm{y}) \neq(0,0)$, the Hamiltonian system (2) has no infinite singular points.

For the cases $n>m$ and $n<m$ we have respectively $\mathrm{yP}_{2 \mathrm{n}-1}(\mathrm{x}, \mathrm{y})-\mathrm{xQ}_{2 \mathrm{n}-1}(\mathrm{x}, \mathrm{y})=-\mathrm{na}^{2}\left(\mathrm{x}^{2 \mathrm{n}}+\mathrm{y}^{2 \mathrm{n}}\right) \neq 0$ and $\mathrm{yP}_{2 \mathrm{~m}-1}(\mathrm{x}, \mathrm{y})-\mathrm{xQ}_{2 \mathrm{~m}-1}(\mathrm{x}, \mathrm{y})=-\mathrm{mb}^{2}\left(\mathrm{x}^{2 \mathrm{~m}}+\mathrm{y}^{2 \mathrm{~m}}\right) \neq 0$ for $(\mathrm{x}, \mathrm{y}) \neq(0,0)$. Therefore again the Hamiltonian system has no infinite singular points, and $\mathbb{S}^{1}$ is a periodic orbit of the Poincaré compactification of system (2).

In summary we know that all the finite singular points of system (2) are centers, and that it has no infinite singular points. Moreover, since this system is polynomial it has finitely many singular points, therefore by the Poincaré-Hopf Theorem (Theorem 5) applied to the Poincaré sphere, we obtain that two times the sum of the indices of the finite singular points is equal to 2. One of the "two times" comes from the northern open hemisphere and the other from the south open hemisphere of the Poincare sphere because we have a copy in each of these hemispheres of our system (2). Hence since the sum of the indices of all the finite singular points is 1 , and each center has index 1 , the system has a unique center, which we denote by c.

To end the proof applying Theorem 3 we must prove that the local center $\mathrm{c}$ is global. But for applying Theorem 3 we need that $F(0,0)=(0,0)$, so we consider the map $\bar{F}=T \circ F$, where $T(x, y)=(x-a, y-b)$ if $\mathrm{F}(0,0)=(\mathrm{a}, \mathrm{b})$. Then the map $\overline{\mathrm{F}}$ satisfies $\overline{\mathrm{F}}(0,0)=(0,0)$ and also satisfies all the conditions of the map $\mathrm{F}$ given in the statement of Theorem 1 . So we shall prove that $\overline{\mathrm{F}}$ is injective, and consequently $\mathrm{F}$ will be injective. In what follows for simplifying the notation we denote $\overline{\mathrm{F}}$ by $\mathrm{F}$.

Let $\mathrm{W}_{\mathrm{c}}$ be the period annulus of $\mathrm{c}$. If the last periodic orbit of $\mathrm{W}_{\mathrm{c}}$ is the infinity in the Poincare disc we are done. Assume that $\gamma$ is the last periodic orbit of $\mathrm{W}_{\mathrm{c}}$ and that it does not coincide with the periodic orbit at $\mathbb{S}^{1}$, and let $\mathrm{p}$ be a point of $\gamma$. Consider the Poincaré map $\Pi: \Sigma_{0} \rightarrow \Sigma$ associated to $\gamma$, where $\Sigma$ is a local transverse section to the vector field associated to system (2) through the point $p$, for further information on these topics see chapter 1 of Dumortier et al. (2006). Here $\Sigma_{0}$ denotes the domain of definition of the map $\Pi$ on the section $\Sigma$. 
By Proposition 1.21 of Dumortier et al. (2006) the map $\Pi$ is analytic because system (2) is polynomial. Clearly the map $\Pi$ restricted to the part of $\Sigma_{0}$ contained in the period annulus $\mathrm{W}_{\mathrm{c}}$ is the identity. Therefore, since $\Pi$ is an analytic map of one variable, it is analytic in the whole $\Sigma_{0}$. Hence $\gamma$ cannot be the last periodic orbit of $\mathrm{W}_{\mathrm{c}}$, a contradiction. Consequently the center is global and by Theorem 3 we conclude that $\mathrm{F}=(\mathrm{f}, \mathrm{g})$ is injective.

Proposition 4.2 of Cima and Llibre (1990) states:

Proposition 6. Let $\mathrm{P}$ and $\mathrm{Q}$ be two real homogeneous polynomials of degree $\mathrm{n}$ in the variables $\mathrm{x}$ and $\mathrm{y}$. Assume that $\mathrm{P}$ and $\mathrm{Q}$ do not have real common factors, that $\mathrm{xQ}(\mathrm{x}, \mathrm{y})-\mathrm{y} \mathrm{P}(\mathrm{x}, \mathrm{y})$ has no real linear factors, and that

$$
\int_{-\infty}^{+\infty} \frac{\mathrm{P}(1, \mathrm{y})}{\mathrm{Q}(1, \mathrm{y})-\mathrm{y} \mathrm{P}(1, \mathrm{y})} \mathrm{dy}=0 .
$$

Then the phase portrait of the polynomial vector field (P,Q) is a global center.

Proof of Theorem 2. Under the assumptions of Theorem 2, first we shall see that the polynomial xQ(x,y)$\mathrm{yP}(\mathrm{x}, \mathrm{y})$ has no real linear factors. By the Euler's Theorem for homogeneous functions we have that

$$
x Q-y P=x\left(f f_{x}+g g_{x}\right)+y\left(f f_{y}+g g_{y}\right)=n\left(f^{2}+g^{2}\right) .
$$

Therefore since the homogeneous polynomials $\mathrm{f}$ and $\mathrm{g}$ has no real linear factors in common, the homogeneous polynomial $\mathrm{xQ}(\mathrm{x}, \mathrm{y})-\mathrm{yP}(\mathrm{x}, \mathrm{y})$ also does not have a real linear factor. Hence, from the hypotheses of Theorem 2 all the assumptions of Proposition 6 are satisfied. Consequently the Hamiltonian system with Hamiltonian $\mathrm{H}=\left(\mathrm{f}^{2}+\mathrm{g}^{2}\right) / 2$ has a global center. So by Theorem 3 we get that the polynomial map $F=(f, g)$ is injective. We note that as in the proof of Theorem 1, for applying Theorem 3 we need that $\mathrm{F}(0,0)=(0,0)$, again taking the map $\overline{\mathrm{F}}=\mathrm{T} \circ \mathrm{F}$, where $\mathrm{T}(\mathrm{x}, \mathrm{y})=(\mathrm{x}-\mathrm{a}, \mathrm{y}-\mathrm{b})$ if $\mathrm{F}(0,0)=(\mathrm{a}, \mathrm{b})$, we verify that $\overline{\mathrm{F}}(0,0)=(0,0)$ and that $\overline{\mathrm{F}}$ satisfies the conditions of the map $\mathrm{F}$ given in the statement of Theorem 2 . So we apply Theorem 3 to the map $\overline{\mathrm{F}}$, and we obtain the injectivity for the map $\overline{\mathrm{F}}$, and consequently for the map F.

\section{ACKNOWLEDGMENTS}

We thank to the reviewer his/her comments which help us to improve the presentation of our results. The first author is supported by a Fundação de Amparo à Pesquisa do Estado de São Paulo (FAPESP) grant number 2016/23285-9. The second author is supported by a MINECO-FEDER grant MTM2016-77278-P, a MINECO grant MTM2013-40998-P, and an AGAUR grant number 2014SGR-568.

\section{AUTHORS CONTRIBUTIONS}

J. Llibre conceived of the presented idea and supervised the findings of this work. J. Llibre and J. Itikawa developed the theory and performed the necessary analyses. Both authors discussed the results and contributed to the final manuscript. 


\section{REFERENCES}

BRAUN F, GINÉ J AND LLIBRE J. 2016. A sufficient condition in order that the real Jacobian conjecture in R2 holds. J Differential Equations 260(6): 5250-5258.

BRAUN F AND LLIBRE J. 2015. A new qualitative proof of a result on the real jacobian conjecture. An Acad Bras Cienc 87: 1519-1524.

BRAUN F AND LLIBRE J. 2017. On the connection between global centers and global injectivity. Preprint .

CIMA A AND LLIBRE J. 1990. Algebraic and topological classification of the homogeneous cubic vector fields in the plane. J Math Anal Appl 147(2): 420-448.

DUMORTIER F, LLIBRE J AND ARTÉS J. 2006. Qualitative theory of planar differential systems. Berlin Heidelberg: Spring-Verlag.

ESSEN AVD. 2000. Polynomial automorphisms and the Jacobian conjecture, Progress in Mathematics 190. Basel: Birkhauser Verlag.

KELLER OH. 1939. Ganze Cremona-Transformationen. Monatsh Math Phys 47(1): 299-306.

PINCHUK S. 1994. A counterexample to the strong real Jacobian conjecture. Math Z 217(1): 1-4.

SABATINI M. 1998. A connection between ishochronous Hamiltonian centres and the Jacobian Conjecture. Nonlinear Anal 34: 829-838. 